\title{
Use of the cotton leaf curl Multan alphasatellite as a silencing or expression vector
}

\author{
M. S. SHAHID ${ }^{1,2}$, S. MANSOOR ${ }^{1}$, R. W. BRIDDON ${ }^{1}$
}

\begin{abstract}
${ }^{1}$ Agricultural Biotechnology Division, National Institute for Biotechnology and Genetic Engineering, Faisalabad, Pakistan; ${ }^{2}$ Department of Crop Sciences, College of Agricultural and Marine Sciences, Sultan Qaboos University, Al-Khod 123, Oman
\end{abstract}

Received May 15, 2018; accepted May 30, 2018

\begin{abstract}
Summary. - Alphasatellites, formerly known as DNA 1, are a satellite-like components associated with begomoviruses (the family Geminiviridae) that require betasatellite for symptom induction but depend on DNA-A for systemic movement. We have converted alphasatellite into gene-silencing vector (modified alphasatellite ( $\triangle \mathrm{DNA} 1)$ ) by deleting its A-rich region that does not affect the replication nor the movement of the helper virus. Insertion of a transgene green florescence protein (GFP) into $\triangle \mathrm{DNA} 1$ resulted in the silencing $\mathrm{g}$ of the cognate gene in Nicotiana benthamiana. The silencing persisted for more than one and half month and was associated with the decreased level of mRNA of the target gene. This satellite-like DNA vector induced gene silencing (VIGS) promises to be applicable to other begomovirus/alphasatellite systems, thereby providing the powerful approach to gene discovery and the analysis of gene functions in malvaceous crops.
\end{abstract}

Keywords: cotton; begomovirus; alphasatellite; RNAi

\section{Introduction}

Gene expression in plants, animals and fungi can be suppressed by RNA silencing (also known as RNA interference [RNAi]), which is mediated in these organisms by a mechanism that involves sequence-specific mRNA degradation (Waterhouse and Helliwell, 2003). In plants, a procedure known as virus-induced gene silencing (VIGS) has emerged as a powerful method for studying gene functions (Baulcombe, 1999; Waterhouse and Helliwell, 2003). Typically, VIGS is induced by infecting a plant with a plant virus with its genome modified to include a sequence identical to that of the mRNA transcribed from the host target gene. However, this procedure has some limitations. Most applications of VIGS have been studied in model hosts such

E-mail: mshahid@squ.edu.om, shafiqinayat@gmail.com; phone: +968-24141209.

Abbreviations: CLCuMA = cotton leaf curl Multan alphasatellite; $\mathrm{CLCuMB}=$ cotton leaf curl Multan betasatellite; CLCuMV = cotton leaf curl Multan virus; $\mathrm{CP}=$ coat protein; $\mathrm{CpCDV}=$ chickpea chlorotic dwarf virus; $\mathrm{dpi}=$ days post inoculation; ToLCNDV = tomato leaf curl New Delhi virus; VIGS = vector induced gene silencing as Nicotiana benthamiana and Arabidopsis thaliana. Virus vectors used in these systems may not have important crop plants as hosts. Also, the efficiency of silencing depends on the virus-host combination or gene silencing may not occur in all hosts of the virus. In some cases, the virus vector may cause symptoms in plants that may mask the phenotype caused by silencing of the target gene.

Viruses of the genus Begomovirus (the family Geminiviridae) are whitefly-transmitted, plant-infecting pathogens with genomes that consist of either one or two molecules of circular single-stranded (ss)DNA (Brown et al., 2012). For bipartite begomoviruses, with components known as DNA-A and DNA-B, both components are required for infectivity of plants. The single component forming the genome of monopartite begomoviruses (which is a homolog of the DNA-A components of bipartite begomoviruses) is sufficient for symptomatic infection of plants, although monopartite begomoviruses are believed to be phloem limited (Rojas et al., 2001), due to the lack of additional movement functions encoded by DNA-B whereas bipartite begomoviruses may infect tissues beyond the phloem (Wang et al., 1996). In the Old World, most begomoviruses have monopartite genomes and the majority of these are associated with 
symptom modulating ssDNA satellites known collectively as betasatellites (formerly DNA $\beta$ ) (Briddon and Stanley, 2006; Briddon et al., 2008). Betasatellites are approx. 1350 nucleotides long and are, in some cases, required by their helper begomoviruses to systemically infect the hosts from which they were isolated (Briddon et al., 2001; Saunders et al., 2000). The majority of begomovirus-betasatellite complexes are also associated with additional ssDNA components, the alphasatellites (previously known as DNA 1) (Briddon and Stanley, 2006; Briddon et al., 2004).

Alphasatellite components are satellite-like, circular ssDNA molecules approx. 1375 nucleotides long (Briddon et al., 2004). They encode a single gene, a rolling circle-replication initiator protein (Rep) and are capable of autonomous replication in permissive plant cells, however they require a helper begomovirus for movement within and between plants (Mansoor et al., 1999; Saunders and Stanley, 1999). They are closely related to the Rep-encoding components of nanoviruses (a second family of plant-infecting ssDNA viruses (Vetten et al., 2004)), from which they are believed to have evolved (Briddon and Stanley, 2006). Interestingly, all alphasatellites so far investigated are phenotypically silent, playing no part in the pathogencity of the complex with which they are associated. Although no definitive function has been ascribed to alphasatellites, their presence in plants infected with begomovirus-betasatellite complexes may reduce virus and/or betasatellite DNA levels and possibly attenuate symptoms (Wu and Zhou, 2005; Ali et al., 2011). Nawaz-ul-Rehman et al. (2010) have shown that at least some, alphasatellites encode Rep proteins with the ability to suppress post-transcriptional gene silencing - meaning that they may be involved in overcoming host defences based upon RNAi.

The components and satellites of begomoviruses form an ideal basis for the construction of VIGS vectors. Lessons learnt from the construction of VIGS vectors from non-malvaceous begomoviruses point to the construction of successful vectors for use in the family Malvaceae. Thus, vectors based on the DNA-A component of the bipartite viruses utilize the coat protein $(\mathrm{CP})$ gene replacement strategy, while for a betasatellite the $\beta \mathrm{C} 1$ gene replacement strategies. The use of an alphasatellite transcription fusion vector, using a New World bipartite (viruses with mild symptoms) helper virus (such as cotton leaf crumple virus), is a promising system. The ability of VIGS vectors based on geminiviruses to induce gene silencing even in fruit and the meristem offer great advantages over VIGS vectors based on RNA viruses. The ultimate aim with any VIGS vector is an infectious unit which causes no (or only mild) symptoms in plants; so as not to mask the phenotypic effect of silencing of the target gene. Efforts to adapt the cotton leaf curl disease-associated alphasatellite component for use as a VIGS and expression vector are reported here.

\section{Methods and Materials}

Production of alphasatellite-based vectors. Three constructs were produced based upon the cotton leaf curl Multan alphasatellite (CLCuMA-[PK:Fai1:98]; Acc. No. AJ132344; Mansoor, 1999). Modifications were introduced into the CLCuMA sequence by PCR-mediated mutation using the oligonucleotide primers (Table 1). The primers were designed to introduce a restriction endonuclease recognition sequence, either at the 5 'end of the Rep coding sequence (yielding CLCuMA ${ }^{\mathrm{N}}$ with an $M l u \mathrm{I}$ site; using primers $D N A 1^{\mathrm{N}} \mathrm{F}$ and $\mathrm{DNA} 1^{\mathrm{N}} \mathrm{R}$ ) or at the $3^{\prime}$ end of the Rep coding sequence (yielding CLCuMA ${ }^{\mathrm{C}}$ with an $M l u \mathrm{I}$ site; using primers $\mathrm{DNA}^{\mathrm{C}} \mathrm{F}$ and $D N A 1^{C} R$ ). A further mutant, CLCuMA ${ }^{\triangle A}$, was produced with the A-rich sequence of the alphasatellite, replacing it with a ClaI recognition sequence (using primers DNA $1^{\text {mut }} \mathrm{F}$ and $\mathrm{DNA} 1^{\mathrm{mut}} \mathrm{R}$ ). PCR (Taq DNA Polymerase, Thermo Fisher, USA) reactions used standard conditions as, an initial denaturation for $3 \mathrm{~min}$ at $95^{\circ} \mathrm{C}$; followed by 35 cycles of denaturation at $95^{\circ} \mathrm{C}$ for $45 \mathrm{~s}$, annealing at $55^{\circ} \mathrm{C}$ for $35 \mathrm{~s}$, and extension at $72^{\circ} \mathrm{C}$ for $45 \mathrm{~s}$; and final extension was at $72{ }^{\circ} \mathrm{C}$ for $10 \mathrm{~min}$.) and the recircularised (BamH1 restriction site) insert of the alphasatellite clone as the template. Resultant PCR products were cloned into pTZ57R/T (Fermentas, USA) and the clones were sequenced to ensure that there were no additional mutations introduced by the mutagenesis procedure (Fig. 1).

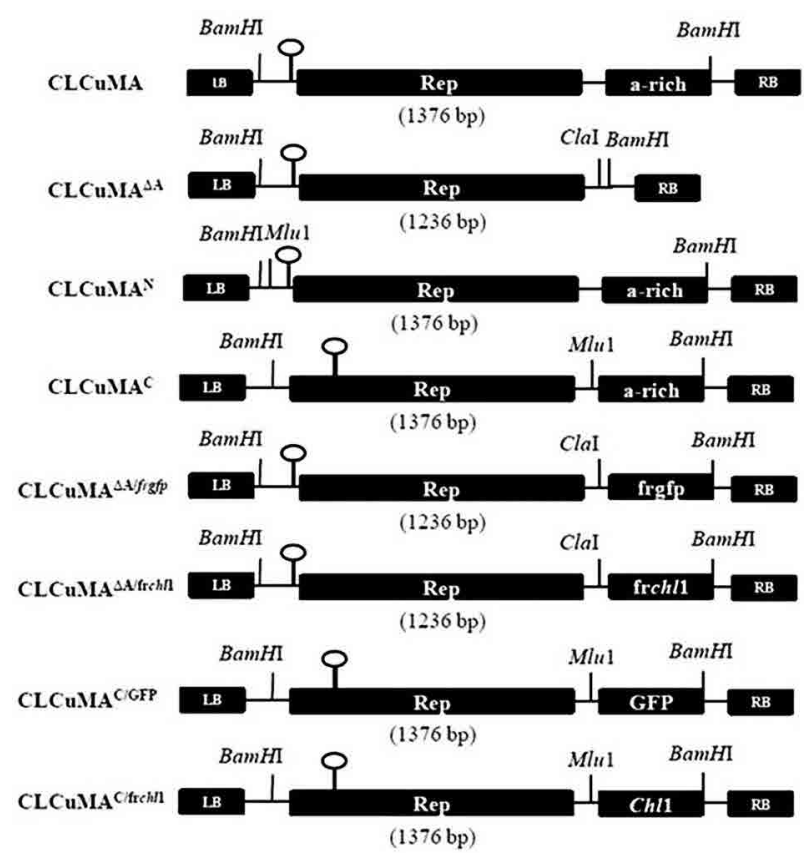

Fig. 1

Alphasatellite constructs

For the CLCuMA ${ }^{\triangle \mathrm{A}}$ vector, the A-rich region was replaced with ClaI restriction site. CLCuMA ${ }^{\mathrm{N}}$ was produced by inserting an Mlul restriction site at the $5^{\prime}$ end of the start codon of the Rep gene whereas for CLCuMA ${ }^{\mathrm{C}}$ an $M l u I$ site was introduced in to the $3^{\prime}$ end of the Rep gene. GFP and Chll constructs were produced and shown accordingly. 
Table 1. Primers used for production of CLCuMA constructs and amplification of GFP and Chl1

\begin{tabular}{|c|c|}
\hline Primer name & Primer sequence \\
\hline $\mathrm{DNA} 1^{\mathrm{mut}} \mathrm{F}$ & ATATCGATAAAAAATCAGGCCCCGCAG \\
\hline $\mathrm{DNA} 1^{\mathrm{mut}} \mathrm{R}$ & ATCATCGATAGGTCCTTCAGCAAAGTGA \\
\hline DNA $1^{\mathrm{N}} \mathrm{F}$ & TTCACGCGTTCTCTCTCTTCTGTGTTC \\
\hline DNA $1^{\mathrm{N}} \mathrm{R}$ & AGAACGCGTGAAAGGCACGAGGGAAC \\
\hline $\mathrm{DNA} 1^{\mathrm{C}} \mathrm{F}$ & GGTACGCGTTGTAATTTTAAAAGACT \\
\hline DNA $1^{\mathrm{C}} \mathrm{R}$ & CAACGCGTACCCCAAAACTTTCAATAT \\
\hline GFPF & ATCGATGGTGATGTTAATGGGCAC \\
\hline GFPR & ATCGATGTCATGCCGTTTCATATG \\
\hline Chl182F & ATCGATCTGAGGGTGTCAAGGCATTT \\
\hline Chll427R & ATCGATTTCCGAATCGATCAAGAAGC \\
\hline ChlMF & ACGCGTCTGAGGGTGTCAAGGCATTT \\
\hline ChlMR & ACGCGTTTCCGAATCGATCAAGAAGC \\
\hline GFP56F & ACGCGTTCAAGGAGGACGGAAACATC \\
\hline GFP785R & ACGCGTAAAGGGCAGATTGTGTGGAC \\
\hline
\end{tabular}

Production of constructs for Agrobacterium-mediated inoculation. A partial direct repeat construct of CLCuMA ${ }^{\triangle \mathrm{A}}$ was prepared by digesting the clone with $\mathrm{ClaI}$ and BamHI to release an approx. 1120 bp fragment which was ligated into the binary vector pGreen0029 (Hellens et al., 2000). The pGreen0029 clone was then digested with ClaI and the full length $\mathrm{CLCuMA}^{\triangle \mathrm{A}}$ insert was ligated as a ClaI fragment. A similar strategy was used to produce partial direct repeat constructs of CLCuMA ${ }^{\mathrm{N}}$ and $\mathrm{CLCuMA}^{\mathrm{C}}$ using $M l u \mathrm{I}$ and BamHI restriction sites.

Origin and cloning of gene/gene fragments for silencing/expression. An approximately $200 \mathrm{bp}$ fragment of the GFP gene was PCR amplified from Nicotiana benthamiana line 16c (Ruiz, 1998) and inserted into the partial direct repeat construct of CLCuMA ${ }^{\triangle \mathrm{A}}$, to yield CLCuMA ${ }^{\triangle \mathrm{A} / \mathrm{frg} g \mathrm{fp}}$, using primers GFP56F and GFP785R (Fig. 1; Table 1). A similar strategy and size of a magnesium chelatase subunit I (ChlI) gene fragment (amplified using primers ChlIF182F and ChlI427R; based upon the sequence of the gene of Gossypium hirsutum [Acc. No. EU541445]) was amplified from G. hirsutum to produce CLCuMA ${ }^{\Delta \mathrm{A} / \mathrm{frchl} 1}$ and CLCuMA ${ }^{\mathrm{C} / \mathrm{frchl} 1}$ at the Mlu1 site (Fig. 1). For the construction of the GFP expression vector based on CLCuMA, a 729 bp fragment from pSMRSGFP (Acc. No. U70496; Davis SJ, 1998) was amplified using primers GFPF and GFPR and inserted into the partial direct repeat construct of $\mathrm{CLCuMA}^{\mathrm{C}}$ to yield CLCuMA ${ }^{\text {C/GFP. }}$

Origins of geminivirus clones used for infectivity studies. Constructs for the Agrobacterium-mediated inoculation of the monopartite begomovirus cotton leaf curl Multan virus (CLCuMV), the betasatellite cotton leaf curl Multan betasatellite (CLCuMB), the bipartite begomovirus tomato leaf curl New Delhi virus (ToLCNDV) and the mastervirus chickpea chlorotic dwarf virus strain C (CpCDV; previously known as Chickpea chlorotic dwarf Pakistan virus) have been described previously (Hussain et al., 2007; Nahid et al., 2008; Amin et al., 2011). Plants were inoculated by infiltration as previously described (Amin et al., 2011).

\section{Results}

\section{Production and testing of constructs}

To investigate the potential for using an alsphasatellite as the basis for a VIGS vector, three distinct mutants were produced using CLCuMA as the template. The first involved the insertion of an $M l u$ I restriction site upstream of the ATG codon of the Rep gene of the alphasatellite (yielding $\mathrm{CLCuMA}^{\mathrm{N}}$; Fig. 1). The second involved the introduction of an MluI restriction site downstream of the Rep gene $\left(\mathrm{CLCuMA}^{\mathrm{C}}\right)$. Both constructs were designed to allow the insertion of foreign gene sequences which would be expressed as a transcription fusion gene of the Rep gene. The third construct, CLCuMA ${ }^{\triangle \mathrm{A}}$, involved replacement of the Arich region with a ClaI restriction site (Fig. 1), to investigate whether foreign sequences at this distance from the end of the Rep gene could be incorporated in the Rep mRNA, and thus induce silencing, and to investigate whether an alphasatellite is infectious to plants even without the A-rich sequence (thereby potentially increasing the size of a foreign insertion that could be tolerated, see later discussion).

The three constructs were agroinoculated to N. benthamiana with either CpCDV, ToLCNDV or CLCuMV (in both the presence and absence of CLCuMB) (Table 2). For these inoculations the wild-type CLCuMA was inoculated as a control. Neither CLCuMA nor any of the constructs based on CLCuMA were maintained in N. benthamiana by CpCDV. $\mathrm{CLCuMA}^{\mathrm{N}}$ was not maintained by any of the helper viruses.

Table 2. Results of the inoculation of $N$. benthamiana with CLCuMA (and its derivatives) in the presence of distinct helper viruses

\begin{tabular}{|c|c|c|}
\hline \multirow[t]{2}{*}{ Inoculum ${ }^{*}$} & \multicolumn{2}{|c|}{$\begin{array}{l}\text { No. of plants containing alphas- } \\
\text { atellite / No. of plants infected / } \\
\text { No. of plants inoculated }\end{array}$} \\
\hline & Exp.1 & Exp.2 \\
\hline CLCuMV + CLCuMB + CLCuMA & $6 / 6 / 6$ & $5 / 5 / 6$ \\
\hline 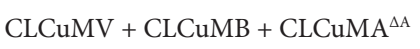 & $6 / 6 / 6$ & $5 / 5 / 6$ \\
\hline CLCuMV + CLCuMB + CLCuMA & $0 / 5 / 6$ & $0 / 6 / 6$ \\
\hline $\mathrm{CLCuMV}+\mathrm{CLCuMB}+\mathrm{CLCuMA}^{\mathrm{C}}$ & $6 / 5 / 6$ & $3 / 4 / 6$ \\
\hline CLCuMV + CLCuMA & $3 / 4 / 6$ & $5 / 5 / 6$ \\
\hline $\mathrm{CLCuMV}+\mathrm{CLCuMA}^{\triangle \mathrm{A}}$ & $5 / 5 / 6$ & $4 / 5 / 6$ \\
\hline CLCuMV + CLCuMAN & $0 / 4 / 6$ & $0 / 4 / 6$ \\
\hline CLCuMV + CLCuMA ${ }^{\mathrm{C}}$ & $3 / 5 / 6$ & $4 / 4 / 6$ \\
\hline $\mathrm{ToLCNDV}^{*}+$ CLCuMA & $3 / 5 / 6$ & $2 / 6 / 6$ \\
\hline $\mathrm{ToLCNDV}^{*}+\mathrm{CLCuMA}^{\triangle \mathrm{A}}$ & $4 / 5 / 6$ & $4 / 6 / 6$ \\
\hline $\mathrm{ToLCNDV}^{*}+\mathrm{CLCuMA}^{\mathrm{N}}$ & $0 / 6 / 6$ & $0 / 5 / 6$ \\
\hline $\mathrm{ToLCNDV}^{*}+\mathrm{CLCuMA}^{\mathrm{C}}$ & $3 / 5 / 6$ & $2 / 5 / 6$ \\
\hline CpCDPKV + CLCuMA & $0 / 3 / 6$ & $0 / 4 / 6$ \\
\hline CpCDPKV + CLCuMAN & $0 / 5 / 6$ & $0 / 4 / 6$ \\
\hline CpCDPKV + CLCuMA ${ }^{\triangle A}$ & $0 / 3 / 6$ & $0 / 4 / 6$ \\
\hline CpCDPKV + CLCuMA ${ }^{\mathrm{c}}$ & $0 / 4 / 6$ & $0 / 5 / 6$ \\
\hline
\end{tabular}

${ }^{*}$ Both the DNA-A and DNA-B components of ToLCNDV were inoculated. 

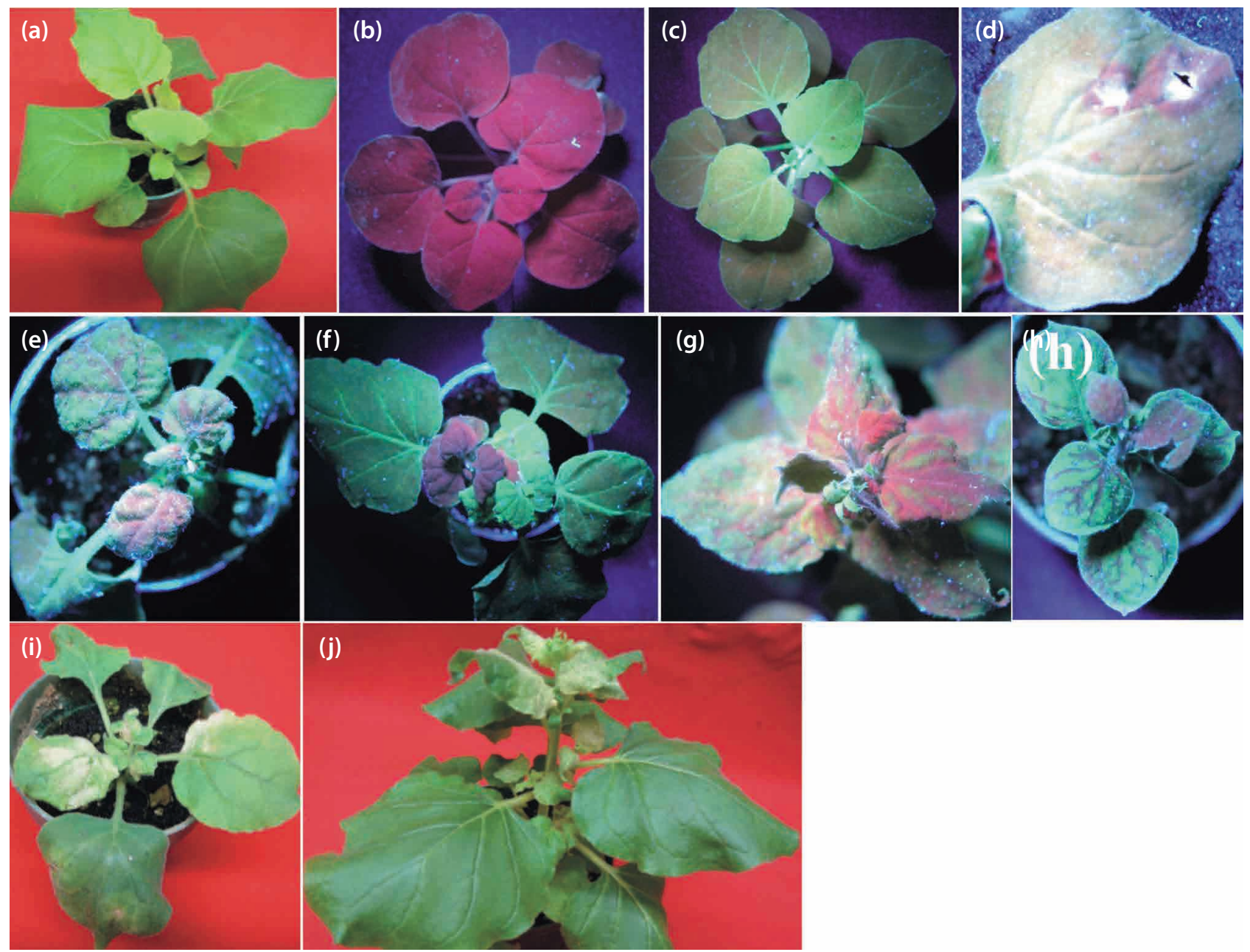

Fig. 2

Transgene GFP and endogenous gene ChlI silencing in $16 \mathrm{c}$ and wild type $N$. benthamiana plants

(a) N. benthamiana plant under visible light; (b) N. benthamiana plant under UV light; (c) GFP transgenic N. benthamiana plant (16c) under UV light; (d) $16 \mathrm{c}$ inoculated with CLCuMA ${ }^{\triangle A / f r g} g f$ and CLCuMV showing local silencing; (e) $16 \mathrm{c}$ inoculated with CLCuMA ${ }^{\triangle A / f r g} f p$ and CLCuMV showing systemic leaf silencing; (f) 16c inoculated with CLCuMV, CLCuMB and CLCuMA ${ }^{\Delta A / f r g f f} ;$ (g) GFP silencing with CLCuMV, CLCuMB and CLCuMA ${ }^{\Delta A / f r g s p}$; (h) GFP silencing with ToLCNDV DNA-A+DNA-B and CLCuMA ${ }^{\Delta A / f r g f f}$; (i) Chl1 silencing with CLCuMA ${ }^{\Delta A / f r c h l}$ and CLCuMV in N. benthamiana and (j) Chl1 silencing with CLCuM ${ }^{\text {AC/frchll }}$, CLCuMV and CLCuMB in N. benthamiana. Photographs were taken at 24 and $32 \mathrm{dpi}$.

Upon these findings CLCuMA ${ }^{\mathrm{N}}$ was not used for the further studies (Table 2).

CLCuMA constructs were efficiently maintained by CLCuMV, both in the presence and absence of CLCuMB, and by ToLCNDV (Table 2). This indicates that the introduced mutations, in each case, have not affected the ability of the molecule to replicate autonomously and be moved in trans, by the respective viruses.

The symptoms induced in each case (16 to 18 days for CpCDV, 22 to 25 days for ToLCNDV, after three weeks for CLCuMV and 14 to 16 for CLCuMV in the presence of CLCuMB) were indistinguishable from the symptoms in the absence of the aphasatellite (or mutated alphasatellite). This is in agreement with earlier reports which demonstrated that the presence of an alphasatellite does not significantly affect symptoms, although possibly a slight reduction in virus DNA levels was detected (personal observation).

\section{Alphasatellite vector-mediated silencing of GFP}

Initial investigation of the possibility of adapting CLCuMA for use as a silencing vector used the well established GFP silencing system that is based upon $N$. benthamiana line $16 \mathrm{c}$ (Ruiz, 1998). This contains a stable GFP transgene expressed under the control of the constitutive promoter $35 \mathrm{~S}$ derived from cauliflower mosaic virus (CaMV). 16c plants appear 
green under UV illumination due to GFP fluorescence (Fig. 2, panel c). In contrast, (non-transgenic) N. benthamiana emits red light under UV illumination due to chlorophyll autofluorescence (Fig. 2, panel b).

Inoculation of CLCuMA ${ }^{\triangle A / f r g f p}$, in the presence of CLCuMV, to $16 \mathrm{c}$ led to typical symptoms of infection at approximately 24 days. Maintenance of the alphasatellite construct was shown by PCR amplification in 13 plants of 18 inoculated. Under UV illumination, silencing at the site of inoculation was evident at 13 days post inoculation (dpi). This appeared as a red area around the infiltration site (Fig. 2, panel d). Within $18 \mathrm{dpi}$, some silencing was present on leaves that were developing at the time of inoculation. This appeared as silencing of the GFP along the veins. Silencing in these leaves was not complete. The leaves above this, developing after inoculation, initially showed silencing along the veins continuing to spread to the whole leaf surface (Fig. 2, panel e). All subsequently developing tissues were entirely silenced; thus, appearing red under UV illumination. The silencing was persistent, remaining until the plants senesced.

A similar result was obtained when CLCuMA ${ }^{\Delta \mathrm{A} / \mathrm{fr} g f p}$ was inoculated in the presence of CLCuMV and CLCuMB. In this case the symptoms of infection appeared after 14 to 16 days. Symptoms were more severe, as is typical for the infections in the presence of a betasatellite (Briddon et al., 2001). In this case maintenance of the alphasatellite vector was detected in 5 plants of 6 inoculated. Silencing progressed more rapidly and was more complete than in the plants inoculated only with CLCuMV. Tissues at the top of the plant showed initial silencing at 13 days post inoculation, in comparison to 18 days for the infection in the absence of CLCuMB (Fig. 2, panels $\mathrm{f}, \mathrm{g})$.

In contrast, inoculation of CLCuMA ${ }^{\Delta \mathrm{A} / \mathrm{fr} g \mathrm{gp}}$ with ToLCNDV DNA-A and DNA-B yielded relatively mild infection with less pronounced leaf curling. Also, the silencing induced was significantly delayed over infection involving CLCuMV. For ToLCNDV, initial symptoms of infection appeared 21 to 24 dpi. Again, there was a halo of silencing visible around the site of inoculation at approx. $17 \mathrm{dpi}$. This spread to noninoculated tissues by $20 \mathrm{dpi}$ (Fig. 2, panel h). However, the plants did not show as bright red as those inoculated with CLCuMV, suggesting that silencing was not complete (some GFP fluorescence remained). Maintenance of the alphsatellite vector was detected in 10 of 18 inoculated plants by PCR.

\section{Alphasatellite vector-mediated silencing of an endogenous gene}

As the transgenes are the more favorable to gene silencing than the endogenous genes (Fagard and Vaucheret, 2000; Ruiz, 1998), we have decided to test the ability of alphasatellite base vector CLCuMA ${ }^{\Delta \mathrm{A} / \text { frchll }}$ to silence the endogenous gene magnesium chelatase subunit I (chl1).
Table 3. N. benthamiana plants showing silencing and expression using GFP and ChlI genes

\begin{tabular}{|c|c|c|c|}
\hline \multirow[t]{2}{*}{ Constructs } & \multicolumn{3}{|c|}{$\begin{array}{l}\text { No. of plants silenced / } \\
\text { No. of plants inoculated }\end{array}$} \\
\hline & Exp.1 & Exp.2 & Exp.3 \\
\hline $\mathrm{CLCuMV+CLCuMA} \triangle \mathrm{A} / \mathrm{fr} g f p$ & $4 / 6$ & $5 / 6$ & $4 / 6$ \\
\hline CLCuMV+ CLCuMB+ CLCuMA ${ }^{\Delta \mathrm{A} / \mathrm{fr} g f p}$ & $5 / 6$ & $6 / 6$ & $4 / 6$ \\
\hline CLCuMV+ CLCuMB + CLCuMA ${ }^{\Delta A} /$ frChl 1 & $5 / 6$ & $4 / 6$ & $6 / 6$ \\
\hline CLCuMV+ CLCuMB+ CLCuMA / frChl1 & $5 / 6$ & $4 / 6$ & $4 / 6$ \\
\hline $\mathrm{ToLCNDV}^{\mathrm{A}+\mathrm{B}}+\mathrm{CLCuMA}^{\Delta \mathrm{A} / \mathrm{fr} g f p}$ & $3 / 6$ & $2 / 6$ & $5 / 6$ \\
\hline${ }^{*} \mathrm{CLCuMV}+\mathrm{CLCuMB}+\mathrm{CLCuMA} / \mathrm{GFP}$ & $3 / 5$ & $2 / 5$ & $2 / 5$ \\
\hline
\end{tabular}

${ }^{*} \mathrm{CLCuMA}{ }^{\mathrm{C} / \mathrm{GFP}}$ used as an expression vector.

Inoculation of CLCuMA ${ }^{\Delta \mathrm{A} / \mathrm{frchl1}}$, in the presence of CLCuMV and CLCuMB, to N. benthamiana led to typical symptoms of infection at approximately 14 to 16 days. Maintenance of the alphasatellite construct was shown by PCR amplification in 15 plants of 18 inoculated (Table 3). Silencing at the site of inoculation was evident at $10 \mathrm{dpi}$. This appeared as a white area around the infiltration site (Fig. 2, panel i). Within $13 \mathrm{dpi}$, some silencing was present on leaves that were developing at the time of inoculation. This appeared as bleaching along the veins. Silencing in these leaves was not complete. The leaves above this, developing after inoculation, initially showed silencing along the veins but this spread to the whole leaf surface. All subsequently developing tissues were entirely silenced; thus, appearing white. The silencing was persistent, remaining until the plants senesced.

In comparison, in the presence of CLCuMV and CLCuMB inoculation of CLCuMA ${ }^{\mathrm{C} / \text { frchl1 }}$, to $N$. benthamiana a similar result was obtained. Also, the silencing induced was delayed a few days over infections involving $\mathrm{CLCuMA}^{\mathrm{C} / \mathrm{frchl} 1}$. For $\mathrm{CLCuMA}^{\mathrm{C} / \mathrm{frchl} 1}$, initial silencing appeared $11 \mathrm{dpi}$. There was a halo of silencing visible around the site of inoculation at approx. $13 \mathrm{dpi}$. This spread to non- inoculated tissues by $16 \mathrm{dpi}$ (Fig. 2, panel j). However, the plants did not show much silencing in case of CLCuMA ${ }^{\mathrm{C} / \text { frchll }}$ than $\mathrm{CLCuMA}^{\Delta \mathrm{A} / \mathrm{frchl} \text {, }}$ suggesting that silencing was not complete (some Chl1 remaining). Maintenance of the alphasatellite vector was detected in 13 of 18 inoculated plants by PCR.

\section{Alphasatellite mediated expression of GFP in plants}

To investigate the potential of CLCuMA for using as an expression vector, the full length GFP gene was inserted in sense orientation into $\mathrm{CLCuMA}^{\mathrm{C}}$ to yield CLCuMA ${ }^{\mathrm{C} / \mathrm{GFP}}$. This construct was agroinoculated to $N$. benthamiana in the presence of CLCuMV and CLCuMB. Typical symptoms of CLCuMV infection in the presence of CLCuMB appeared at approximately 14 to $16 \mathrm{dpi}$. Control plants inoculated with only CLCuMV and CLCuMB, when viewed under UV 

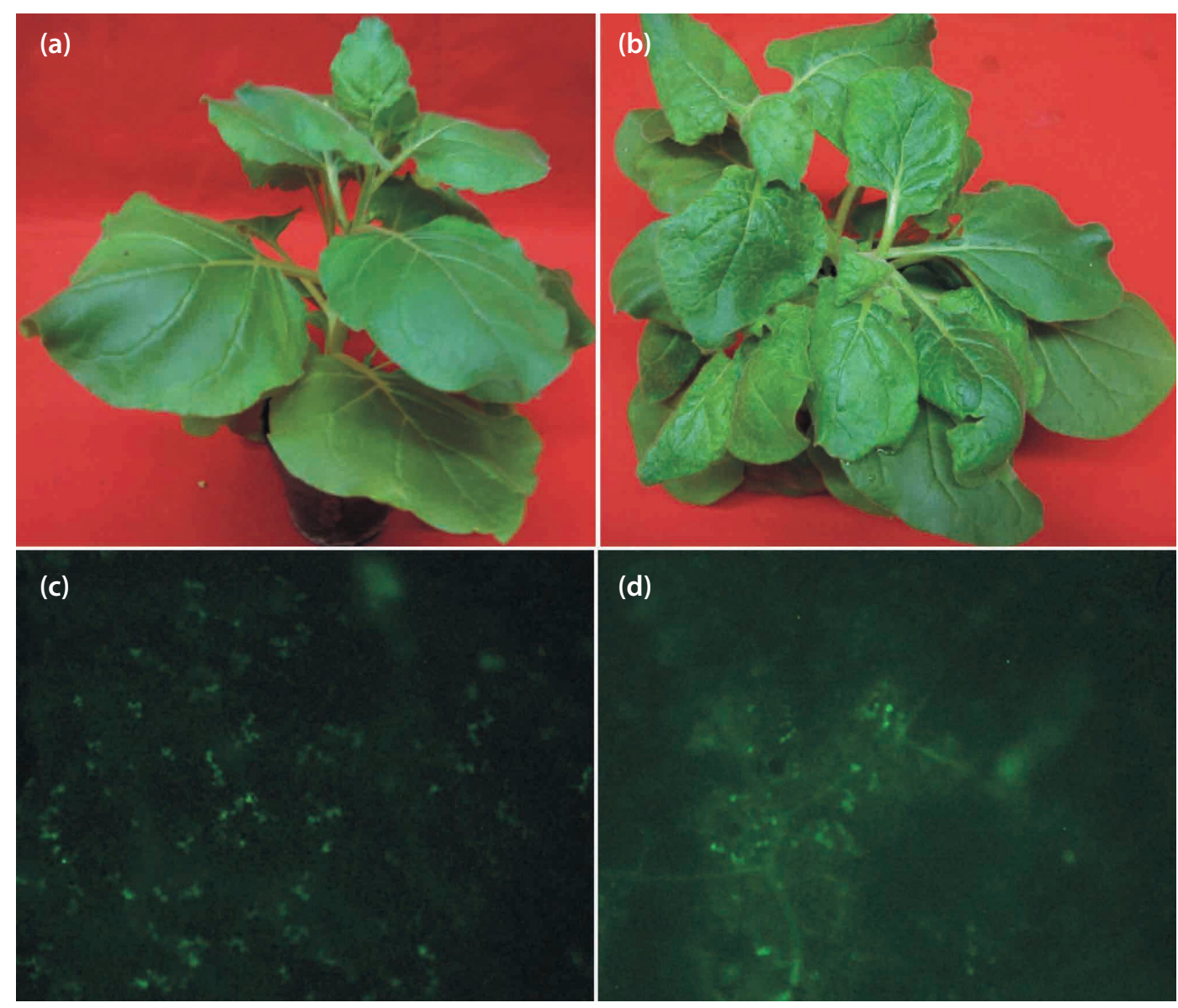

Fig. 3

Detection of GFP fluorescence in $N$. benthamiana inoculated with CLCuMV, CLCuMB and CLCuMA $/ g f f$

(a) mock-inoculated N. benthamiana control; (b) N. benthamiana inoculated with CLCuMV, CLCuMB and CLCuMA ${ }^{\mathrm{C} / f f}$; (c) green fluorescence in inoculated leaf and (d) GFP detection in systemic leafs after 4 weeks of agroinoculation.

illumination, showed red fluorescence due to chlorophyll autofluorescence. In contrast, $N$. benthamiana inoculated with CLCuMV, CLCuMB and CLCuMA ${ }^{\mathrm{C} / g f p}$ showed green fluorescence under UV illumination at the site of inoculation. This fluorescence was first visible approx. 13 days post inoculation and at that time symptoms of infection were/ were not visible on the plants. However, under the confocal microscope GFP fluorescence was clearly visible in tissues developing after inoculation. In a leaf which was just expanding at the time of inoculation (Fig. 3, panel c) faint GFP fluorescence was visible. In subsequently developing leaves clear GFP fluorescence was evident (Fig. 3, panel d). This was closely associated with the veins and did not extend away from vascular tissues. This is likely due to the fact that monopartite begomoviruses are phloem-limited (Rojas et al., 2001). In case of CLCuMV in the presence of the CLCuMB, the symptoms induced (enations and leaf-like outgrowths on the major veins on the undersides of leaves, Briddon et al., 2001) would suggest that this is probably the case that GFP did not extend away to the veins.

\section{Discussion}

The results presented here indicate that an alphasatellite can be used as the basis for a vector for VIGS. Both $\mathrm{CLCuMA}^{\triangle \mathrm{A} / \mathrm{fr} g f p}$ and CLCuMA ${ }^{\mathrm{C} / \mathrm{fr} g f p}$, carrying fragments of the gfp gene in antisense orientation, were capable of silencing GFP expression in N. benthamiana 16c when maintained by begomoviruses. To further validate the vectors, a fragment of ChlI was introduced into CLCuMA ${ }^{\mathrm{C}}$ and inoculated to $N$. benthamiana. This yielded bleaching in systemic leaves characteristic of the loss of chlorophyll, providing a visible marker for gene silencing. The results confirmed that the vector is capable of initiating silencing of an endogenous gene in N. benthamiana. 
The reason for the inability of CLCuMA ${ }^{\mathrm{N}}$ to systemically infect plants, in the presence of a begomovirus, is unclear. Although only minimal changes were introduced into the alphasatellite sequence ( $M l u \mathrm{I}$ restrictions site) it is possible that this adversely affected the transcription or translation of the Rep gene. Although little is yet known about the maintenance of alphasatellites by begomoviruses, it is likely that high-level replication of these molecules is required for their maintenance, which depends upon the Rep (Mansoor et al., 1999; Zhou, 2013). There is no evidence for a (strong) selection mechanism for alphasatellite maintenance. For betasatellites the $\beta C 1$ gene is an essential factor for infection of the helper begomoviruses; it up-regulates virus titers and is a host range determinant (Saeed, 2005; Zhou, 2013). There is thus a strong selection pressure for maintenance of betasatellites. Maintenance of alphasatellites thus possibly is a "numbers game", plants containing such high levels of the satellite that it is almost always transmitted to the next cell by the virus-encoded movement proteins or to the next plant by the vector of the helper begomovirus. Thus, it is likely that the changes introduced into CLCuMA ${ }^{\mathrm{N}}$ affected Rep expression such that there was no longer sufficient alphasatellite replication for it to be maintained during systemic infection.

The inoculations studies with $\mathrm{CLCuMA}^{\triangle \mathrm{A}}$ indicate that the A-rich sequence is not required for the infectivity or maintenance of CLCuMA. The deleted alphasatellite was maintained in plants in the presence of a begomovirus. This is in agreement with earlier studies that deleted the A-rich sequences from a betasatellite. Betasatellites have a similar A-rich sequence and this was shown not to be required for trans-replication or maintenance (Tao, 2004). The function of the A-rich sequence remains unclear. Upon their first identification it was suggested that the A-rich sequence is merely a "stuffer" required to raise the size of a nanovirus component (from which alphasatellites are believed to have evolved) to half ( 1400 bp) of a begomovirus component ( 2800 bp) (Mansoor et al., 1999; Briddon and Stanley, 2006). Geminiviruses have a strict genome size control mechanism which is believed to act during both movement in plants (mediated by the movement associated proteins; Gilbertson et al., 2003) and for encapsidation - monomeric particles containing half size molecules (Frischmuth et al., 2001). Etessami et al. (1989) showed that an African cassava mosaic virus (ACMV) isolate with deletions across the coat protein gene reverted to wild-type size during infection, likely due to strict size requirements for cell-to-cell spread of the virus. It will be interesting, in the future, to investigate this phenomenon to determine what mechanism is responsible for the size increase. This may provide information on the movement of these sub-genomic molecules in plants and their interactions with their helper begomoviruses.

The reason for the lack of maintenance of CLCuMA and the CLCuMA-derived vectors by CpCDV is unclear. Al- though alphasatellites have been shown to be maintained in plants by viruses with which they are not usually associated, such as the bipartite begomovirus ACMV and the curtovirus beet curly top virus (Saunders et al., 1999, 2002). There are no reports of either the association of alphasatellites with mastreviruses in the field or of the ability of mastreviruses to maintain alphasatellites in plants experimentally. Earlier attempts to see whether the mastrevirus tobacco yellow dwarf virus could maintain CLCuMA were unsuccessful (R.W. Briddon, unpublished results). One possible constraint to the maintenance of alphasatellites by mastreviruses is size. Mastreviruses are typically smaller ( $2600 \mathrm{bp})$ than begomoviruses ( $2800 \mathrm{bp}$ ) and alphasatellites could be too large to be encapsidated, being greater than half the size of the genome. However, this would not explain why the A-rich deletion mutant, which is $\sim 140 \mathrm{bp}$, was not maintained by CpCDV. Further studies are required to investigate this finding.

One of the advantages of an alphasatellite vector, over many of the other vectors, is that it can, at least in theory, be used with any begomovirus or even curtovirus (Saunders et al., 2002). Thus, it can possibly be used to investigate gene expression (or as an expression vector) on the entire plant host range of the begomoviruses/curtoviruses. The experiments conducted here illustrate this possibility by showing that GFP can be used for silencing as helper virus for both a bipartite begomovirus (ToLCNDV) and a monopartite begomovirus (CLCuMV; in both the presence or absence of a betasatellite) in N. benthamiana. The ability of a modified alphasatellite to induce gene silencing using several different begomoviruses has also been shown by Huang et al. (2009). In the context of Pakistan, cotton is the main crop species of interest and it is hoped that the vectors produced here will be useful for silencing/expression in this species. However, at this time, we have no inoculation system for this host.

Although the work conducted here has shown the potential usefulness of an alphasatellite vector for gene silencing and expression, one major hurdle remains to be overcome before their full potential can be realized. As mentioned earlier, one of the main requirements for a useful gene silencing vector is that it does not induce appreciable symptoms, which could interfere with interpretation of the silenced phenotype. All the viruses used here induce significant symptoms (Padidam et al., 1995; Amin et al., 2011). Betasatellite-associated begomoviruses, not including the betasatellite (as was shown) can reduce the symptom severity, but they do not entirely abolish symptoms. The next step is thus, to identify means of either abolishing, or at least diminishing, the symptoms induced by potential helper viruses, without significantly affecting their infectivity and ability to systemically move in plants. Ongoing studies into the pathogenicity determinants of begomoviruses may provide possible means to consistently down-regulate symptoms induced by begomoviruses which would make it possible to modify potential helper begomo- 
viruses for silencing studies using the alphasatellite vectors (Amin et al., 2011; Hanley-Bowdoin et al., 2013).

GFP has been used extensively to study the movement of viruses in plants. Coat protein (CP) replacement vectors have, for example, been used to study the movement of the bipartite begomovirus bean dwarf mosaic virus (Sudarshana et al., 1998). These studies made use of the fact that bipartite begomoviruses do not require the $\mathrm{CP}$ for systemic infection of host plants (Stanley and Townsend, 1986; Gardiner et al., 1988; Azzam et al., 1994). However, for monopartite geminiviruses, including monopartite begomoviruses, the CP is essential for infectivity and it likely is providing some essential movement functions - movement of these viruses is either as virions or as CP-DNA complexes (Briddon et al., 1989). This thus precludes the CP replacement strategy for expressing GFP for virus movement studies. An alternative strategy, which may be useful for monopartite begomoviruses and curtoviruses, is to use an alphasatellite vector expressing the GFP. This would overcome any effects of mutation of the virus to facilitate GFP expression. Even for bipartite begomoviruses mutation of the $\mathrm{CP}$ has deleterious effects which may interfere with the interpretation of the results; for example, the time to symptom appearance is extended for bipartite begomoviruses with mutated CP (Klinkenberg et al., 1989). It is thus anticipated that the vector produced here will be useful for studying the movement of monopartite begomoviruses and curtoviruses in planta. Possibly the first use of the vector will be to study the difference between monopartite begomoviruses in the presence and absence of betasatellites, since the $\beta C 1$ gene encoded by betasatellites has been shown to have possible virus movement functions (Saeed et al., 2007).

Acknowledgments. MSS was supported by a $\mathrm{PhD}$ fellowship from the higher Education Commission (HEC), Government of Pakistan. RWB was supported by the HEC under the "Foreign Faculty Hiring Program". The authors are grateful for the support of NIBGE in conducting this study. The authors are also grateful to Dr. Judith K. Brown and Ali M. Idris (University of Arizona, USA) for providing magnesium chelatase subunit I (ChlI) gene and other support.

\section{References}

Ali MI, Shahid MS, Briddon RW, Khan AJ, Zhu JK, Brown JK (2011): An unusual alphasatellite associated with monopartite begomoviruses attenuates symptoms and reduces betasatellite accumulation. J. Gen. Virol. 92, 706-717. https://doi.org/10.1099/vir.0.025288-0

Amin I, Patil BL, Briddon RW, Mansoor S, Fauquet CM (2011): A common set of developmental miRNAs are upregulated in Nicotiana benthamiana by diverse begomoviruses. Virol. J. 8,143. https://doi.org/10.1186/1743-422X-8-143

Azzam O, Frazer J, de la Rosa D, Beaver JS, Ahlquist P, Maxwell DP (1994): Whitefly transmission and efficient ssDNA accumulation of bean golden mosaic geminivirus requires functional coat protein. Virology 204, 289-296. https:// doi.org/10.1006/viro.1994.1533

Baulcombe D (1999): Viruses and gene silencing in plants. Arch. Virol. 15, 189-201.

Briddon RW, Watts J, Markham, PG, Stanley J (1989): The coat protein of beet curly top virus is essential for infectivity. Virology 172, 628-633. https://doi.org/10.1016/00426822(89)90205-5

Briddon RW, Mansoor S, Bedford ID, Pinner MS, Saunders K, Stanley J, Zafar Y, Malik KA, Markham PG (2001): Identification of DNA components required for induction of cotton leaf curl disease. Virology 285, 234-243. https:// doi.org/10.1006/viro.2001.0949

Briddon RW, Stanley J (2006): Sub-viral agents associated with plant single-stranded DNA viruses. Virology 344, 198-210. https://doi.org/10.1016/j.virol.2005.09.042

Briddon RW, Brown JK, Moriones E, Stanley J, Zerbini M, Zhou $X$, Fauquet CM (2008): Recommendations for the classification and nomenclature of the DNA- $\beta$ satellites of begomoviruses. Arch. Virol. 153, 763-781. https://doi. org/10.1007/s00705-007-0013-6

Briddon RW, Bull SE, Amin I, Mansoor S, Bedford ID, Rishi N, Siwatch SS, Zafar MY Abdel-Salam AM, Markham PG (2004): Diversity of DNA 1; a satellite-like molecule associated with monopartite begomovirus-DNA $\beta$ complexes. Virology 324, 462-474. https://doi.org/10.1016/j. virol.2004.03.041

Brown JK, Fauquet CM, Briddon RW, Zerbini M, Moriones E, Navas-Castillo J (2012): Geminiviridae. In King AMQ, Adams MJ, Carstens EB, Lefkowitz EJ (Eds.): Virus Taxonomy. Ninth Report of the International Committee on Taxonomy of Viruses. Associated Press, Elsevier Inc., London, Waltham, San Diego, pp. 351-373.

Davis SJ, Vierstra RD (1998): Soluble derivatives of green fluorescent protein (GFP) for use in Arabidopsis thaliana. http:// www.ncbi.nlm.nih.gov/nuccore/U70496.

Etessami P, Watts J, Stanley J (1989): Size reversion of African cassava mosaic virus coat protein gene deletion mutants during infection of Nicotiana benthamiana. J. Gen. Virol. 70, 277-289. https://doi.org/10.1099/0022-1317-70-2-277

Fagard M, Vaucheret H (2000): Systemic silencing signal(s). Plant Mol. Biol. 43, 285-293. https://doi.org/10.1023 /A:1006404016494

Frischmuth T, Ringel M, Kocher C (2001): The size of encapsidated single-stranded DNA determines multiplicity of African cassava mosaic virus particles. J. Gen. Virol. 82, 673-676. https://doi.org/10.1099/0022-1317-82-3-673

Gardiner WE, Sunter G, Brand L, Elmer JS, Rogers SG, Bisaro DM (1988): Genetic analysis of tomato golden mosaic virus: the coat protein is not required for systemic spread or symptom development. EMBO J. 7, 899-904. https://doi. org/10.1002/j.1460-2075.1988.tb02894.x

Gilbertson RL, Sudarshana M, Jiang H, Rojas MR, Lucas WJ (2003): Limitations on geminivirus genome size imposed by plasmodesmata and virus-encoded movement protein: Insights into DNA Trafficking. Plant Cell 15, 2578-2591. https://doi.org/10.1105/tpc.015057 
Hellens RP, Edwards EA, Leyland NR, Bean S, Mullineaux PM (2000): pGreen: a versatile and flexible binary Ti vector for Agrobacterium-mediated plant transformation. Plant Mol. Biol. 42, 819-832. https://doi. org/10.1023/A:1006496308160

Hanley-Bowdoin L, Bejarano ER, Robertson D, Mansoor S (2013): Geminiviruses: masters at redirecting and reprogramming plant processes. Nat. Rev. Micro. 11, 777-788. https://doi.org/10.1038/nrmicro3117

Huang C, Xie Y, Zhou X (2009): Efficient virus-induced gene silencing in plants using a modified geminivirus DNA1 component. Plant Biotechnol J. 7, 254-265. https://doi. org/10.1111/j.1467-7652.2008.00395.x

Hussain M, Mansoor S, Iram S, Zafar Y, Briddon RW (2007): The hypersensitive response to tomato leaf curl New Delhi virus nuclear shuttle protein is inhibited by transcriptional activator protein. Mol. Plant-Microbe Interact. 20, 1581-1588. https://doi.org/10.1094/MPMI-20-12-1581

Klinkenberg A, Ellwood S, Stanley J (1989): Fate of African cassava mosaic virus coat protein deletion mutants after agroinoculation. J. Gen. Virol. 70, 1837-1844. https:// doi.org/10.1099/0022-1317-70-7-1837

Mansoor S, Khan SH, Bashir A, Saeed M, Zafar Y, Malik KA, Briddon RW, Stanley J, Markham PG (1999): Identification of a novel circular single-stranded DNA associated with cotton leaf curl disease in Pakistan. Virology 259, 190-199. https://doi.org/10.1006/viro.1999.9766

Nahid N, Amin I, Mansoor S, Rybicki EP, Van-der WE, Briddon RW (2008): Two dicot-infecting mastreviruses (family Geminiviridae) occur in Pakistan. Arch. Virol. 153, 1441-1451. https://doi.org/10.1007/s00705-008-0133-7

Nawaz-ul-Rehman MS, Nahid N, Mansoor S, Briddon RW, Fauquet CM (2010): Post-transcriptional gene silencing suppressor activity of two non-pathogenic alphasatellites associated with a begomovirus. Virology 405, 300-308. https:// doi.org/10.1016/j.virol.2010.06.024

Padidam M, Beachy RN, Fauquet CM (1995): Tomato leaf curl geminivirus from India has a bipartite genome and coat protein is not essential for infectivity. J. Gen. Virol. 76, 25-35. https://doi.org/10.1099/0022-1317-76-1-25

Rojas MR, Jiang H, Salati R, Xoconostle-Cázares B, Sudarshana MR, Lucas WJ, Gilbertson RL (2001): Functional analysis of proteins involved in movement of the monopartite begomovirus, tomato yellow leaf curl virus. Virology 291, 110-125. https://doi.org/10.1006/viro.2001.1194

Ruiz MT, Voinnet O, Baulcombe DC (1998): Initiation and maintenance of virus-induced gene silencing. Plant Cell 10, 937-946. https://doi.org/10.1105/tpc.10.6.937

Saeed M, Behjatnia SAA, Mansoor S, Zafar Y, Hasnain S, Rezaian MA (2005): A single complementary-sense transcript of a geminiviral DNA $\beta$ satellite is determinant of pathogenicity. Mol. Plant-Microbe Interact. 18, 7-14. https:// doi.org/10.1094/MPMI-18-0007
Saeed M, Zafar Y, Randles JW, Rezaian MA (2007): A monopartite begomovirus-associated DNA $\beta$ satellite substitutes for the DNA B of a bipartite begomovirus to permit systemic infection J. Gen. Virol. 88, 2881-2889. https://doi. org/10.1099/vir.0.83049-0

Saunders K, Bedford ID, Briddon RW, Markham PG, Wong SM, Stanley J (2000): A unique virus complex causes ageratum yellow vein disease. Proc. Natl. Acad. Sci. USA 97, 6890-6895. https://doi.org/10.1073/pnas.97.12.6890

Saunders K, Stanley J (1999): A nanovirus-like component associated with yellow vein disease of Ageratum conyzoides: evidence for interfamilial recombination between plant DNA viruses. Virology 1, 142-152. https://doi. org/10.1006/viro.1999.9948

Saunders K, Bedford ID, Stanley J (2002): Adaptation from whitefly to leafhopper transmission of an autonomously-replicating nanovirus-like DNA component associated with ageratum yellow vein disease. J. Gen. Virol. 83, 909-915. https://doi.org/10.1099/0022-1317-83-4-907

Sudarshana, MR, Wang, HL, Lucas, WJ, Gilbertson, RL (1998): Dynamics of bean dwarf mosaic geminivirus cell-tocell and long-distance movement in Phaseolus vulgaris revealed, using the green fluorescent protein. Mol. PlantMicrobe Interact. 11, 277-291. https://doi.org/10.1094/ MPMI.1998.11.4.277

Stanley, J, Townsend, R (1986): Infectious mutants of cassava latent virus generated in vivo from intact recombinant DNA clones containing single copies of the genome. Nucleic Acids Res. 14, 5981-5999. https://doi.org/10.1093/ $\underline{\text { nar/14.15.5981 }}$

Tao, X, Qing, L, Zhou, X (2004): Function of A-rich region in DNA $\beta$ associated with Tomato yellow leaf curl China virus. Chin. Sci. Bull. 49, 1490-1493. https://doi. org/10.1360/04wc0132

Vetten HJ, Chu PWG, Dale JL, Harding R, Hu J, Katul L, Kojima M, Randles JW, Sano Y, Thomas JE (2004): Nanoviridae. In (Fauquet CM, Mayo MA, Maniloff J, Desselberger U, Ball LA (Eds): Virus Taxonomy, VIIIth Report of the ICTV. Elsevier/Academic Press, London, UK, pp. 343-352.

Wang HL, Gilbertson RL, Lucas WJ (1996): Spatial and temporal distribution of bean dwarf mosaic geminivirus in Phaseolus vulgaris and Nicotiana benthamiana. Phytopathology. 86, 1204-1214. https://doi.org/10.1094/Phyto-86-1204

Waterhouse PM, Helliwell CA (2003). Exploring plant genomes by RNA-induced gene silencing. Nat. Rev. Genet. 4, 29-38. https://doi.org/10.1038/nrg982

Wu P, Zhou X (2005): Interaction between a nanovirus-like component and the tobacco curly shoot virus/satellite complex. Acta. Biochim. Biophys. Sin. 37, 25-31. https:// doi.org/10.1093/abbs/37.1.25

Zhou X (2013): Advances in understanding begomovirus satellites. Ann. Rev. Phytopathol. 51, 357-381. https://doi. org/10.1146/annurev-phyto-082712-102234 